\title{
The Devil in Heaven: A Near-Death Experience with both Positive and Negative Facets
}

\author{
Harvey J. Irwin, Ph.D. \\ Barbara A. Bramwell \\ University of New England
}

ABSTRACT: Although the considerable majority of reported near-death experiences (NDEs) are associated with positive affect, there are occasional cases of so-called negative NDEs that are dominated by fear and anguish. The phenomenological status of the negative experiences and their relationship to the more typical positive NDEs have been the subject of increasing speculation. In that light, the NDE described in this paper is of interest because it began to unfold as a positive experience but then changed course to become a negatively toned one. We present the details of this case and note its principal theoretical implications.

Surveys of the near-death experience (NDE) in different countries consistently confirm the overriding positive affect associated with the experience. Most notable in this respect are feelings of tranquility and well-being at the onset of the NDE and a sense of reassurance induced by ostensible contact with a transcendental or "heavenly" realm. The experient (NDEr) may express disappointment, even anger, at having to return to an earthly life but even in such cases the NDE is appreciated as a positive experience.

There is nevertheless a handful of reported cases of NDEs dominated by fear and anguish. Instances of these so-called negative near-death

Dr. Irwin is a Senior Lecturer in Psychology at the University of New England in Australia; Ms. Bramwell is an undergraduate student in the same department. Requests for reprints should be sent to Dr. Irwin at the Department of Psychology, University of New England, Armidale NSW 2351, Australia. 
experiences were brought to the notice of researchers by Maurice Rawlings (1978), and although there initially were doubts about the phenomenological legitimacy of these experiences (e.g., Ring, 1980, p. 194) subsequent evidence from more scientific studies (Grey, 1985) indicated that the negative NDE is an authentic experience occasionally encountered during a close confrontation with death.

The relative rarity of negative NDEs (Gallup, 1982, p. 76) has been a major impediment to their investigation and it is clear there is much yet to be learned about these experiences. Despite the lack of an adequate data base NDE researchers nevertheless are beginning to draw some comparisons between negative and other ("positive," or "core") experiences. Kimberly Clark (cited in Flynn, 1986, pp. 83-86) has implied that whereas positive NDEs enhance religiosity in a universal or nonsectarian sense, negative NDEs tend to convert the experient to a strict Bible-based Christianity; the latter effect might spring from the contact with a hellish environment in many of the negative experiences. Further, Bruce Greyson (personal communication, June 6,1988 ) and others already are speculating that positive and negative NDEs have different origins, that is, they may be quite distinct experiences.

At the same time the gross phenomenological parallelism between positive and negative NDEs is substantial. Like positive experiences, the negative NDE can incorporate impressions of being out of the body (Grey, 1985, pp. 63-64), moving through a dark void or tunnel (Grey, 1985 , p. 69; Sutherland, 1988, p. 20), contact with a being of light (Grey, 1985 , p. 66), and entry into a transcendental realm where deceased acquaintances and religious identities may be met (Grey, 1985 , p. 69; Rawlings, 1978). But within this gross parallelism the two categories of NDE can differ in specific details. For example, the affective quality is distinct in each experience; this of course is the criterion on which positive and negative NDEs are differentiated. There is also an element of judgment associated with negative NDEs. In positive experiences the NDEr feels loved unconditionally by God, and all aspects of one's past life, both good and bad, seem acceptable; in negative NDEs, on the other hand, the experient reports being judged for past deeds either implicitly or explicitly (Grey, 1985, pp. 66-67). Progression through the dark void or tunnel may be disparate too: negative NDErs commonly report the movement to be in a downward direction (Grey, 1985, p. 70; Lindley, Bryan \& Conley, 1981, p. 114; Sutherland, 1988, p. 20), and that is not found in other NDEs. The most dramatic distinction, however, would seem to be in regard to the transcendental realm that may be encountered in the experience. This 
realm in the positive NDE generally is described as a "heavenly" or pastoral setting of preternatural beauty (Irwin, 1987). Negative NDErs on the other hand, typically report the transcendental environment to be a hellish place, a dark, dank, misty cave or a lake of fire and brimstone, for example (Crookall, 1966; Grey, 1985, pp. 68-72; Rawlings, 1978, Ch 7); the devil or other menacing demonic figures may be met in this setting (Lindley et al., 1981, p. 114).

The case reported in this paper is of particular interest in that it appears to incorporate elements of both positive and negative NDEs. The experience begins to unfold as a stereotypically positive, Moodytype case: the experient initially is emotionally detached despite the traumatic state of her physical body; the physical setting is perceived in an out-of-body perspective; and the self moves upward through a tunnel-like structure to the conventional pastoral realm. But within this tranquil pastoral environment there then is an unexpected encounter with the devil and the NDE thenceforth is marked by the affective tone of a negative experience.

The case study was undertaken in April, 1987, as a student project by $\mathrm{BAB}$ under the supervision of HJI. The NDE occurred in the context of a road accident in April, 1981. Vera, the experient, was aged 50 years at the time of the experience and is a divorcée. She attended secondary school education until the age of 15 . Vera reported that as a child she had no religious inclinations; in her early twenties she became a Roman Catholic but even then she never really observed the practice of that faith. Following the NDE Vera has shown an interest in spiritualism and also has attended Salvation Army meetings because she finds them "homely." She still does not embrace any one religious creed but rather has a universal spirituality: there is "just God and love and tolerance." Prior to the accident Vera had no knowledge of NDEs. She has discussed her own experience only with a few close friends.

Vera was interviewed by BAB within the broad guidelines of Kenneth Ring's (1980, pp. 265-268) interview schedule. She also completed two questionnaires, the Death Perspectives Scales (Spilka, Minton, Sizemore \& Stout, 1977) and Ring's (1984, pp. 276-279) Life Changes Questionnaire. For the sake of completeness the principal data on these instruments may be cited briefly at this point. As an indication of the way in which Vera now views death, her scores on the individual dimensions of the Death Perspectives Scales were as follows (higher scores signify greater concurrence): Death as Pain and Loneliness, 2.7; Death as an Afterlife-of-Reward, 5.8; Indifference Toward Death, 2.8; Death as Unknown, 5.2; Death as Forsaking Dependents Plus Guilt, 2.4; Death as Courage, 3.8; Death as Failure, 3.4; Death as a Natural 
End, 4.8. In the Life Changes Questionnaire the greatest change Vera evidenced in her post-NDE life was an increased spiritual orientation and a decreased materialism; she also indicated increased concern for others and a quest for life's meaning. Like both positive and negative NDEs (Irwin, 1988) Vera's experience therefore had a fundamental impact on her beliefs and her attitudes to life and death.

The following account of Vera's experience was compiled from a transcript of the tape-recorded interview with her.

The accident happened on 5th April, 1981. I had been out and I was driving a friend home. It was a very bad night, the weather was really bad and it was raining very hard. I had dropped him off at his home and I made a U-turn to go back up to a main street to go back into town. I did the usual things-looked to see if there were any cars coming - and as I got over the road, halfway across the road, to make another right hand turn ... I never saw any [car] lights but I had the feeling something clipped me and I spun. Being a very rainy night the car had spun and kept spinning, and I can remember trying to put my foot out to stop the car from spinning, but that didn't happen. The car spun and it hit one lamppost and then wrapped around another one. The car was very badly smashed and I was told later it took about an hour to get me out. But I don't remember any of that. I don't remember the police or the ambulance being there.

I had this feeling that I was being lifted up into the air, and I was going up and up and then I heard a voice saying "It's too late." I turned and I could see an ambulance down there and another car, and I could see all this commotion going on and yet I couldn't hear anything. I just thought, "Oh, what's happening down there?" Anyway, I just kept going higher and higher and I couldn't see the commotion down there at all. And then I came to a place. It was like a very big tunnel I was going through, a very large tunnel because it took my whole body length-ways. I floated up the tunnel in a spiral fashion. When I got to the top I came to something that looked like a football field, and it was all very bright and there seemed to be a lot of sandstone, little pebbles and things. It was all light and a very blue sky, and right on the edge of the boundaries there were green trees, very green trees, everything was very green. I thought, "Where am I? What am I doing here? I've been here before." When I was a little girl I used to play in a sort of little round field thing; it wasn't a football field but it was made of white sandstoney stuff, and so when I got to this place I thought I was a little girl again.

I looked around and right in the distance I could see a building. I had the feeling that it was a church, but I couldn't see a steeple on it. I thought that as it was the only thing I could see I should start walking towards it. When I got near to it, [I could see] it had big church doors and there were about seven steps going up to it. I walked very slowly up the steps and the door was just ajar-it wasn't closed and it wasn't wide open. I though I had better go inside. Inside it seemed so long and 
there was a red carpet all the way down. It was a church, and yet it wasn't a church. [It reminded her of a monastery she had seen in a television program.] I started walking down and I was frightened. There were so many pews on each side, and each pew was filled with people wearing black robes with hoods. I couldn't see their faces but if I turned my eyes I could see the inside of the hoods were lined with red. There was no sound at all. I kept walking and walking and then came to three steps which I went up, then walked a little further. I then saw what looked like an altar on which were six silver goblets and a big silver jug. I stood there wondering where I was and what I was doing there, when a door opened to the right of the altar and out came the devil. He came over to the altar, looked me straight in the eye and told me to pick up a goblet. I picked up a goblet and he picked up the big silver jug and started pouring. I saw that what he was pouring from the jug was fire, and I screamed, dropped the goblet and started to run. I just ran and ran. I didn't know where I was running to. And then I saw a big fence, a stone fence, and the gates opened and I passed through. Then I came to another fence made out of iron bars, and that just opened, and again I ran through. All the time I was getting warmer and warmer and brighter and brighter.

And that was it. I woke up and there was a [nursing] sister sitting beside me; she was dressed in dark blue with a white cap and I later learnt that she had been with me all night.

Like other negative NDErs, Vera believes the confrontation with the devil denoted God's judgment of her life, although this impression seems largely a posteriori. She believes the good and the bad in her life before the accident were of equal weight and that she was being asked to suffer a drink from the goblet of fire in order to make the balance favorable. By refusing to comply with the devil's demand she was fated to suffer by way of compensation the physical disabilities that resulted from her car accident. In her own words, she was sent back by God "to drink the cup of fire" before she can return to "that beautiful place."

Further questioning confirmed that during the NDE Vera had felt only calm and peace, free of any worry about the physical trauma of the accident or anything else, until the point when she became aware of the figures in the church and then came face to face with the devil. The case thus had qualities of a positive NDE until the episode in the church, after which the tone of the experience became negative.

In this regard the case study could be instructive for the development of theories about negative NDEs. For example, Vera's experience would not sit well with the notion that positive NDEs and negative NDEs differ so much in their origins that the two types of experience represent fundamentally distinct phenomena. Perhaps the most that could be hoped for within that broad framework would be to develop 
the idea that different phases of NDEs have distinct sets of determinants; under that view certain specific factors might engender a positive tone in some parts of the NDE and other factors might be responsible for negative affect elsewhere in the experience. On the other hand, although such a multicausal approach to the NDE warrants further consideration it must be remembered that the phenomenon does have a strikingly holistic quality. Theoretical accounts therefore must accommodate not only the possibly contrasting phases of the NDE but also the intrinsic coherence of the experience.

\section{References}

Crookall, R. (1966). The study and practice of astral projection. New York: University Books.

Flynn, C. P. (1986). After the beyond: Human transformation and the near-death experience. Englewood Cliffs, NJ: Prentice-Hall.

Gallup, G., Jr., with Proctor, W. (1982). Adventures in immortality: A look beyond the threshold of death. New York: McGraw-Hill.

Grey, M. (1985). Return from death: An exploration of the near-death experience. London: Routledge \& Kegan Paul.

Irwin, H. J. (1987). Images of heaven. Parapsychology Review, 18(1), 1-4.

Irwin, H. J. (1988). Out-of-body experiences and attitudes to life and death. Journal of the American Society for Psychical Research, 82, 237-251.

Lindley, J. H., Bryan, S., and Conley, B. (1981). Near-death experiences in a Pacific Northwest American population: The Evergreen study. Anabiosis, 1, 104-124.

Rawlings, M. (1978). Beyond death's door. Nashville, TN: Nelson.

Ring; K. (1980). Life at death: A scientific investigation of the near-death experience. New York: Coward, McCann \& Geoghegan.

Ring, K. (1984). Heading toward omega: In search of the meaning of the near-death experience. New York: Morrow.

Spilka, B., Minton, B., Sizemore, D., and Stout, L. (1977). Death and personal faith: A psychometric investigation. Journal for the Scientific Study of Religion, 16, 169-178.

Sutherland, C. (1988). The near-death experience: 'Claiming life for the first time.' Pallicom, 8(2), 18-23. 